\title{
Calvarial lesions: overview of imaging features and neurosurgical management
}

\author{
Isabella Nasi-Kordhishti ${ }^{1}$ (D) $\cdot$ Johann-Martin Hempel ${ }^{2} \cdot$ Florian Heinrich Ebner $^{1,3} \cdot$ Marcos Tatagiba $^{1}$
}

Received: 22 January 2021 / Revised: 17 February 2021 / Accepted: 8 March 2021 / Published online: 22 March 2021

(C) The Author(s) 2021

\begin{abstract}
Calvarial lesions are rare and can present as a variety of different diseases. The lesions can be palpable on the skin and cause local pain and paraesthesia and, depending on the location, neurological deficits can also occur. This research aims to present an overview of typical imaging features as well as neurosurgical management. We examined the charts of patients who underwent surgery on a calvarial lesion in our department between 2004 and 2017 (n=133). Retrospectively, the pre-, intra-, and postoperative data were analyzed with morphological and histological findings and compared with each other. Pain, swelling, cosmetically disturbing, and neurological deficits were the main complaints. Seventy-seven lesions were limited to the bone, while another 56 lesions showed an infiltrating growth in the adjacent tissue. Depending on the clinical signs and suspected diagnosis, a biopsy, a partial removal, or a complete resection was performed. Histiocytosis $(n=20)$, meningiomas $(n=20)$, metastases $(n=19)$, and osteomas $(n=16)$ were the most common lesions. Fibrous dysplasia $(n=6)$ and intraosseous hemangioma $(n=9)$ were less common; other lesions were present only in isolated cases. Imaging features may suggest the lesion to be benign or malignant, but the diagnosis can be only confirmed by histological examination. The surgical strategy depends on the complaints, location of the lesion, and suspected diagnosis. Adjuvant treatment should be initiated according to the histological findings.
\end{abstract}

Keywords Calvarial lesions $\cdot$ Imaging $\cdot$ Histiocytosis $\cdot$ Meningiomas $\cdot$ Metastases

\section{Introduction}

Intraosseous lesions of the calvarium are often slow, progressive processes that manifested in swelling, local pain, or sensitivity disorders. Asymptomatic processes are often described as random findings in the imaging. A variety of diseases can hide behind such a lesion. We distinguish between lesions that originate primarily from the bone and those that present a secondary bone infiltration. Depending on the author, the first category is divided into three or four subcategories: primary neoplasia (in individual papers already divided into good and

Isabella Nasi-Kordhishti

isabella.nasi-kordhishti@med.uni-tuebingen.de

1 Department of Neurosurgery, Eberhard Karls University Tübingen, Hoppe-Seyler-Strasse 3, 72076 Tübingen, Germany

2 Department of Neuroradiology, Eberhard Karls University Tübingen, Tübingen, Germany

3 Department of Neurosurgery, Alfried Krupp Hospital, Essen, Germany malignant primary neoplasia), secondary neoplasia, and tumor-like lesions [17, 22]. Using adequate imaging as computed tomography (CT) and magnetic resonance imaging (MRI), suspicions can be drawn about the dignity of the present lesion, especially if the clinical symptoms and the case history of the patients are included $[8,12,14]$. A definitive diagnosis of a lesion can be only made based on histopathological examination. The clinical management methods of calvarial lesions differ greatly depending on the underlying entity [17]. Most benign lesions, such as osteomas, meningiomas, or intraosseous hemangiomas, can usually be completely resected and do not need further treatment $[5,16,18,23]$. However, malignant lesions, such as metastasis or osteolysis in plasmacytoma, potentially require an adjuvant therapy such as chemotherapy, immunotherapy, or radiation [3, 17]. Rare diseases such as histiocytosis require individual diagnostic and therapeutic evaluations $[2,20]$.

Since calvarial lesions are rare diseases in neurosurgery, only a few single-case reports and reviews have been published. This research aims to present an overview of calvarial lesions based on typical imaging features and the histopathological results, as well as the neurosurgical management. 


\section{Materials and methods}

Included are all children and adults with lesion of the clavarium and orbita who were operated in our department between 2004 and 2017. The pre-, intra-, and postoperative data, as well as the imaging and histopathological findings, have been analyzed retrospectively. All patients with solitary lesions at the skull base were excluded. Since this is a surgical series, patients who have been treated only conservatively are not included. This case series does not claim to be a presentation of all possible disease entities.

All statistical tests were performed using JMP 13 (SAS Institute Inc., Cary, NC). Descriptive data are shown as mean, standard deviation (SD), and percentage.

\section{Results}

\section{Pre- and intraoperative evaluation}

A total of 133 patients were operated, 74 of whom were women, and 59 were men. The age distribution of $0-95$ years is homogeneously distributed over all decades with a mean of 42 years and a standard deviation (SD) of 24.7 (Fig. 1a).

The patients' main complaints (Fig. 1b) were swelling $(n=91 ; 68 \%)$, pain $(n=61 ; 46 \%)$, and subjective cosmetic impairment $(n=58 ; 44 \%)$. Rarely represented were focal neurological deficits (FND) $(n=22 ; 17 \%)$, feelings of tension of the skin $(n=21 ; 16 \%)$, exophthalmos $(n=8 ; 6 \%)$, diplopia $(n=7$; $5 \%)$, and dents in the skin $(n=4 ; 3 \%)$. Only 23 patients have not complained of any symptoms.

The location of the lesions is distributed in every part of the skull with a clear frontal prevalence $(n=55 ; 41 \%)$. Parietal $(n=26 ; 19 \%)$, occipital $(n=20 ; 15 \%)$, orbital $(n=12 ; 9 \%)$, sutural $(n=7 ; 5 \%)$, and temporal $(n=4 ; 3 \%)$ lesions are rarer. In two newborns, a lesion was found directly on the fontanel $(1.5 \%)$.

All patients, except the two newborns, have received preoperative cranial imaging using $\mathrm{CT}$ and MRI with and without contrast enhancement. The newborns were dispensed with CT diagnostics. Also, an X-ray, sonography, PET-CT, or bone scintigraphy was performed preoperatively in individual cases. The typical findings for the lesions are described in Table 1 after the classification of the postoperatively obtained histology.

A complete resection has been achieved in $80 \%$ of cases $(n=107)$. A partial removal was performed in $14 \%(n=18)$, a biopsy in $6 \%(n=8)$ of cases. Intraoperative complications have only occurred in a few cases: intraoperative bleeding in 10 patients $(7 \%$; histologically metastasis, meningiomas, epidermal cyst, and melanoma), of which 3 are due to a sinus injury (2\%). Accidental opening of the dura mater occurred in 7 patients $(5 \%)$.
Fifty-eight percent of the lesions $(n=77)$ were limited to the bone. The remaining lesions $(n=56 ; 42 \%)$ have shown an infiltrating growth in the adjacent tissue, especially in the dura in $32 \%$ of cases $(n=43)$. Infiltration up to arachnoid mater has been shown in $1.5 \%$ of cases $(n=2)$, up to the brain in $12 \%$ of cases $(n=16)$. Extracranially, infiltration to the skin has been shown in $10 \%$ of cases $(n=13)$, to the subcutaneous tissue in $4 \%$ of cases $(n=5)$, to the muscles in $1.5 \%$ of cases $(n=2)$, and to the galea in $9 \%$ of cases $(n=12)$. The described macroscopic peculiarities of the respective lesions are listed in Table 1.

\section{Postoperative course}

The final histopathological results are listed in Table 1. Postoperative complications have occurred in $<5 \%$ of cases: cerebrospinal fluid fistula in $4 \%(n=5)$, temporary neurological deficits in $3 \%(n=4)$, sinus thrombosis in $2 \%(n=3)$, wound healing disorders in $1.5 \%(n=2)$, and an epidural hematoma in $0.75 \%$ of cases $(n=1)$. In the documented follow-ups (FU) (3120 months), $10 \%$ of patients $(n=14)$ still reported pain or pressure at the site of surgery, $4 \%(n=5)$ paresthesia, and another $4 \%(n=5)$ still had a slight swelling in the surgical area. No permanent neurological disorders or deaths occurred.

In patients with primary neoplasia $(55 \% ; n=73$; Table 1$)$, a complete resection was performed in $44 \%(n=59)$ of cases without developing a recurrence (FU 3-120 months, mean 32, SD 31). Partial resected meningiomas have a stable residual result in $6 \%(n=8)$ of cases (FU 3-57 months, mean 25, SD 19.4). In $4.5 \%$ of cases $(n=6 ; 5$ meningiomas and 1 epidermoid), there was a recurrence within 12-72 months (mean 29, SD 24). The meningiomas needed an adjuvant therapy, and the recurrent epidermoid has been resected again.

Secondary neoplasia $(18 \% ; n=24$; Table 1$)$ has been completely resected in $7.5 \%(n=10)$ of cases (FU 3-9 months, mean 5, SD 2.5). Adjuvant therapy has occurred in $12 \%$ $(n=16)$ of cases, of which $1.5 \%$ of cases remained stable ( $n=2$, histologically metastases, FU 36 months), $0.75 \%$ decreasing ( $n=1$, histologically plasmacytoma, FU 28 months), and 5\% have shown recurrent growth $(n=7$, histologically metastases, squamous cell carcinoma, and melanoma; FU 3-84 months, mean 34, SD 31). Four percent $(n=5)$ have been operatively resected again, $1.5 \%$ of which $(n=2)$ were only on the scalp (squamous cell carcinoma).

Tumor-like lesions $(27 \% ; n=36$; Table 1$)$ have been completely resected in $19.5 \%$ of cases $(n=26)$ without recurrence (FU 3-114 months, mean 43, SD 35). In $4.5 \%$ of cases ( $n=6$, histologically fibrous dysplasia, Gorham-Stout disease, Paget's disease, histiocytosis; FU 4-95 months, mean 40, SD 39), a further treatment was performed with a stable course. In this group, recurrence has not been observed.

Eight patients $(6 \%)$ got lost from FU. 
Fig. 1 a Age distribution in years. b Preoperative complaints. FND, focal neurological deficits
Age distribution (years)

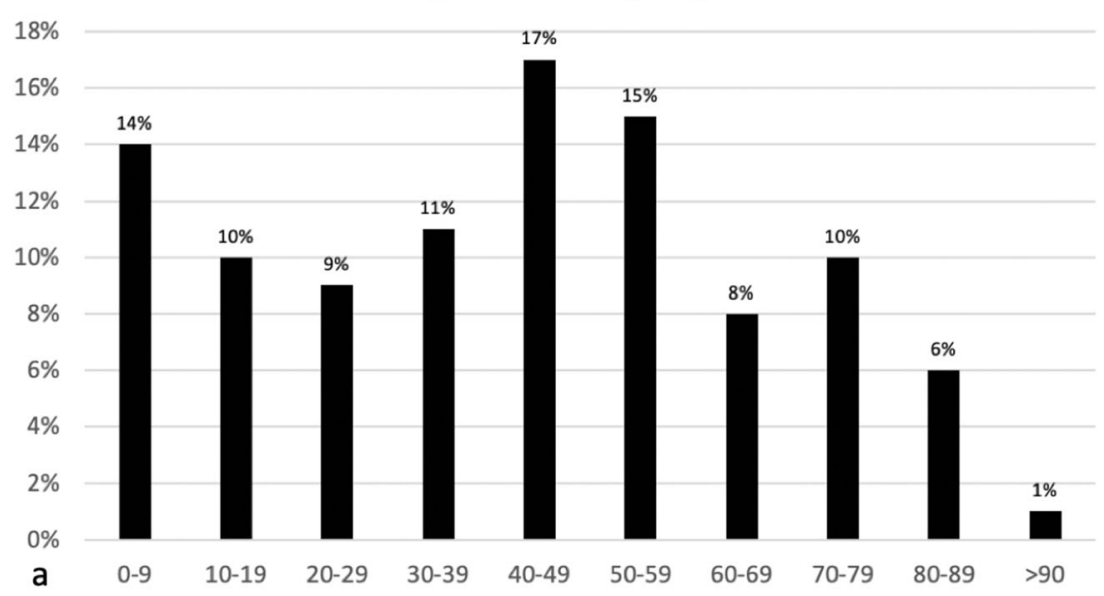

Preoperative complaints (n)

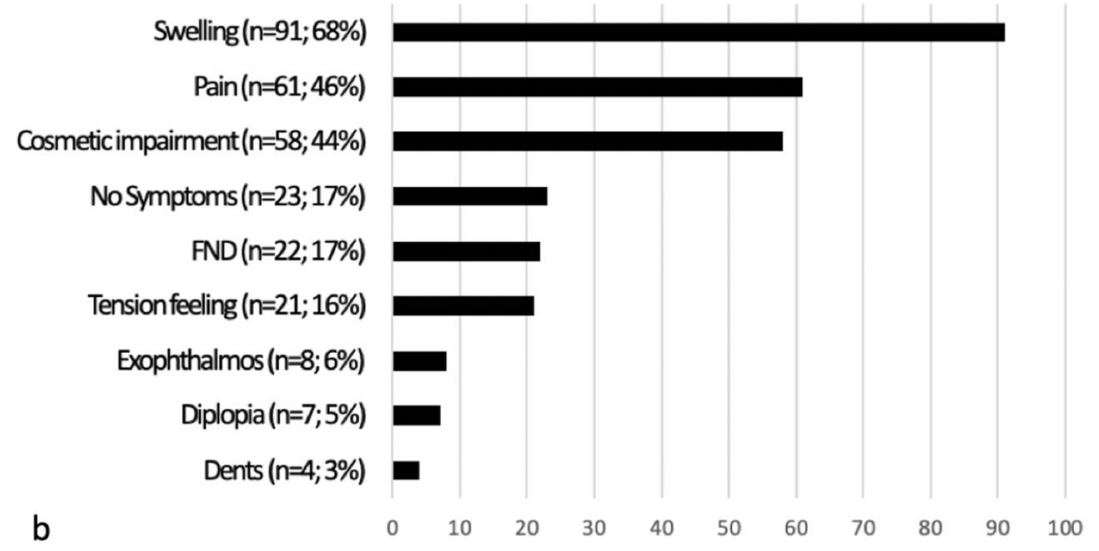

\section{Discussion}

The series of calvarial lesions presented here shows a variety of different entities (Table 1). Their incidence correlates with the cases already published $[8,9,14,17]$. Depending on the author, the lesions that primarily originate from the bone are divided into three or four subcategories: primary neoplasia (in individual papers already divided into good and malignant primary neoplasia), secondary neoplasia, and tumor-like lesions $[17,22]$.

Primary osseous neoplasia come from the bone and are distinguished into benign and malignant lesions. Primary malignant lesions such as chordomas or sarcomas are not represented in our series, since they are frequently located at the skull base. Because a complete resection is not always possible, it is advisable to perform at least one biopsy or extended removal to ensure the diagnosis and initiate adjuvant treatment $[9,10]$. The most common benign lesions include meningiomas (Fig. 2a-d), osteomas (Fig. 2f), and intraosseous hemangiomas (Fig. 2e). Osteomas (Fig. 2f) grow slowly and are located on the tabula externa. The main complaints are the cosmetically disturbing swelling, less than the pain. If they are localized at the orbita, diplopia can occur [1]. Imaging shows a densely compact bone growth. No further treatment is necessary after a complete resection and there is an extremely low risk of recurrence $[8,9,14]$. Intraosseous hemangiomas (Fig. 2e) are described in the literature more in women. As long as they are limited to the bone, they are often an asymptomatic random result $[15,16,18]$. Further growth can cause painful swelling. A typical "sunburst" phenomenon is shown in the CT [18]. In the MRI, a variable arterio-venous contrast enhancement is described [8]. Complete resection down to healthy bone is recommended to minimize the recurrence risk $[8,9,14,15,17,18]$. Meningiomas (Fig. 2a-d) are among the most common benign intracranial tumors. However, about $2 \%$ of meningiomas grow ectopic in the bone and infiltrate the adjacent tissue only secondarily [5, 25]. Typical imaging findings are calcifications, homogeneous contrast enhancement, edema, and a dural tail $[8,9,14]$. Our series includes different WHO grade of meningiomas, which also have significant different infiltrating growth. Adequate preoperative imaging is essential to minimize the intraoperative and postoperative risk 

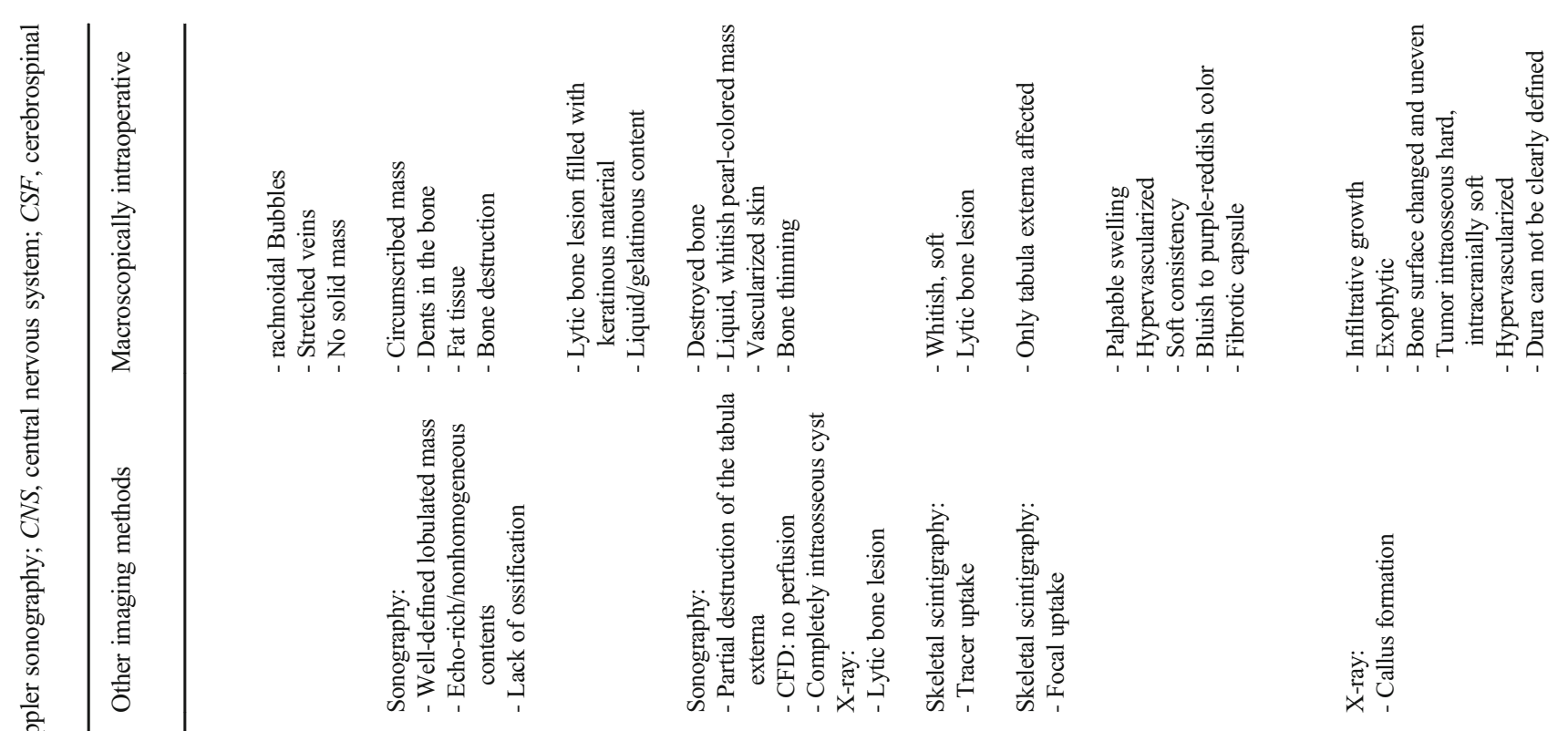

穿先
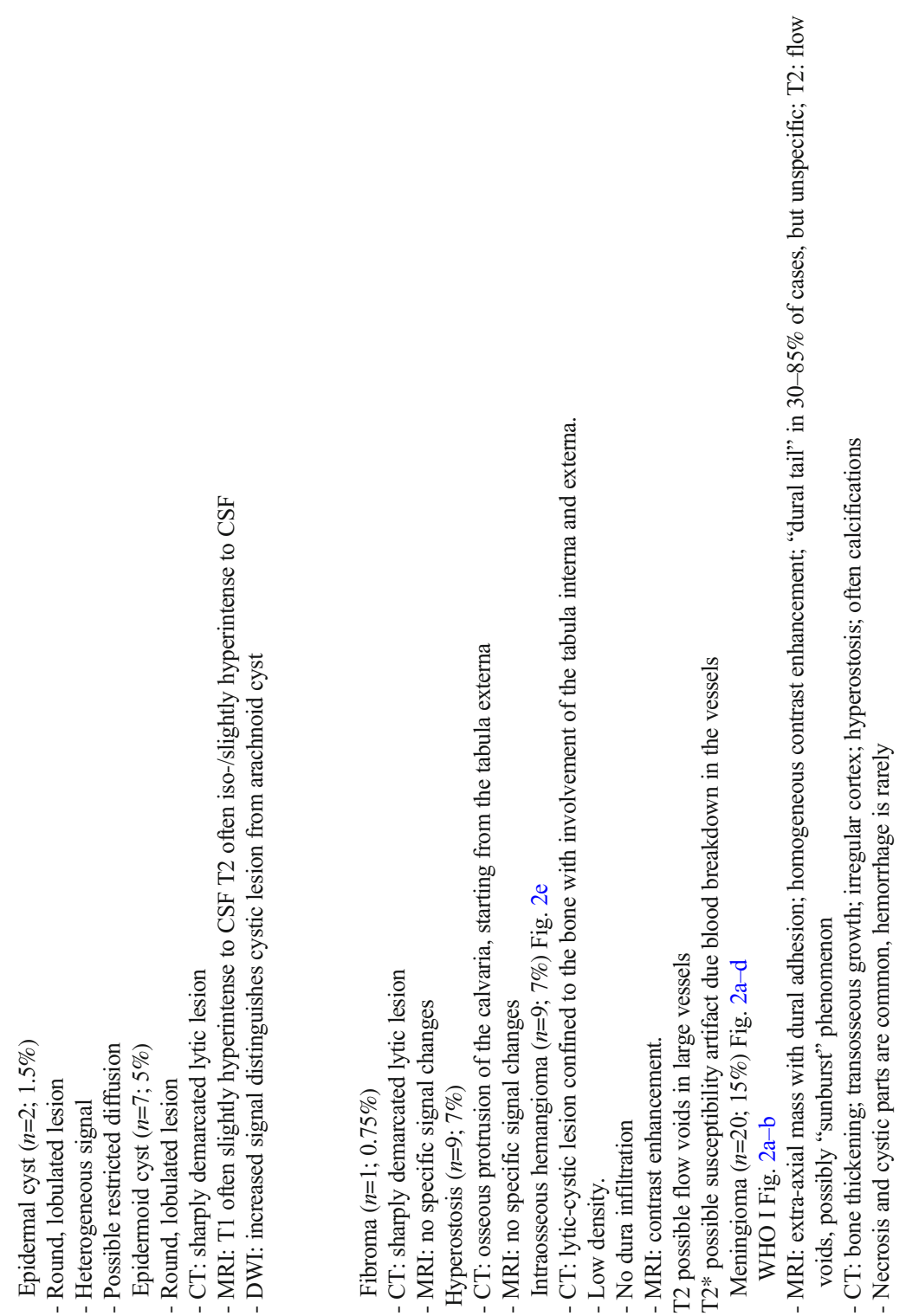


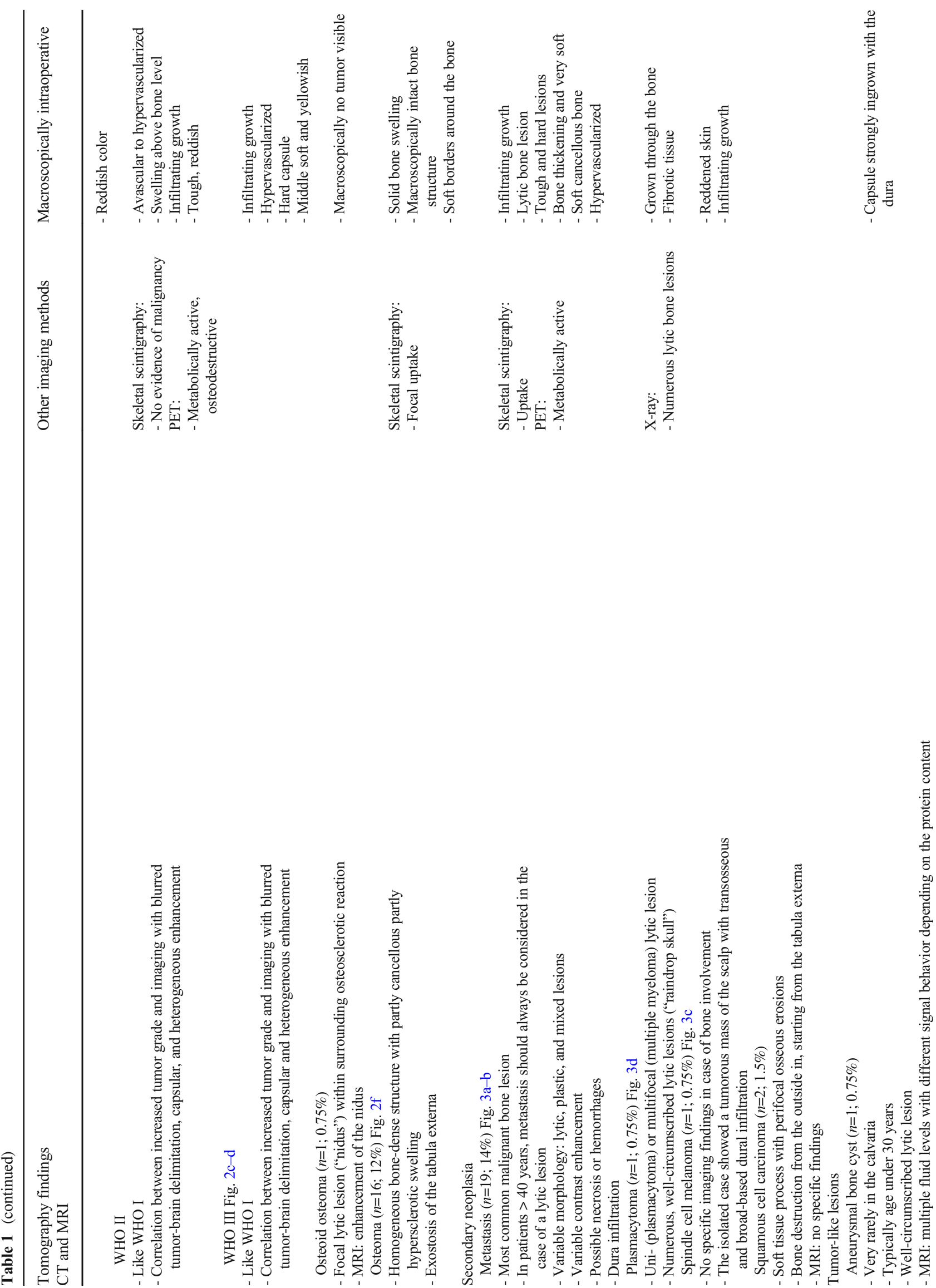




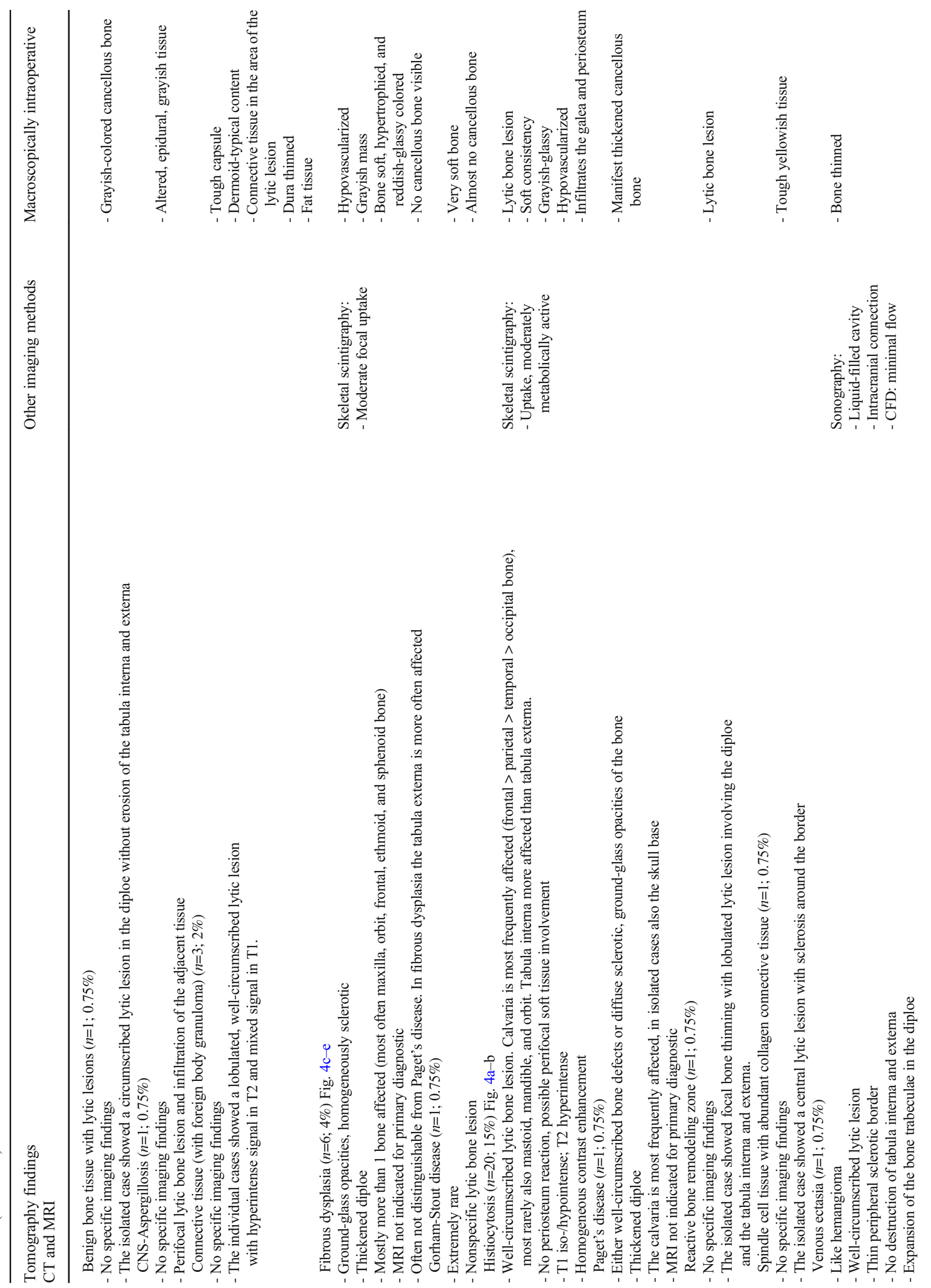


for the patient. A complete resection is also recommended for meningiomas. If this is not possible, appropriate adjuvant therapy should be evaluated depending on the histology [5].

The most common entities of secondary neoplasia are metastasis (Fig. 3a-b) of different primary carcinomas. In most cases, they are asymptomatic and stand out as random findings in the regular staging examinations. Patients can develop pain when the periost is infiltrated. By intracranial growth, the patients can also develop neurological deficits. Typical of the imaging are irregular osteolysis with remodeling of the bone, a variable contrast enhancement, and signs of a co-reaction of the surrounding tissue, for example, a perifocal edema $[8,9$, $14,22]$. A complete resection must be sought, and subsequently, an adjuvant treatment should be started depending on the primary carcinoma $[13,17,22]$. The osteoclastic defects of a plasmacytoma (Fig. 3d) also fall into the category of secondary neoplasia. Typical are pure osteolysis without remodeling of the bone [8]. Surgical resection with cover of the bone defect is recommended. In the event of systemic infestation, further treatment of the disease is necessary. In the scenario of a solitary manifestation and complete surgical resection, close-meshed follow-ups are necessary. In this case, further treatment is controversially discussed in the literature $[3,6,11,19]$. In the case of a histologically secured secondary neoplasia, a staging examination with whole body CT scan should be performed in order to evaluate the spread of the disease and detect other possible bone lesions.

In the group of tumor-like lesions, there are, in particular, histiocytosis (Fig. 4a-b), especially eosinophilic granuloma, and metabolic disorders, such as fibrous dysplasia (Fig. 4c-e). Histiocytosis (Fig. 4a-b) is a group of diseases with an increased proliferation of macrophages. Typical imaging findings are osteolysis with singular bone fragments within the lesion, as a sign of irregular bone destruction. MRI shows a homogeneous contrast enhancement limited to the bone without a co-reaction of the dura or perifocal edema (Table 1) $[8,9$, 20]. The diagnosis can only be secured histologically. After this, a staging should been performed. If the lesion is isolated at the skull, no further therapy is necessary, but for multifocal manifestations, chemotherapy and radiotherapy are recommended $[2,20]$. Another known bone malformation is fibrous dysplasia (Fig. 4c-e), which is due to overactivity of osteoclasts and leads to disturbed bone differentiation [7]. The malformation can affect all bones of the body, including the skull. Patients often complain of severe pain and have swelling or fractures. A distinction is made between the monostotic form (Fig. 4c-d), which can be treated by surgical resection and covering the defect [4], from the polyostotic form (Fig. 4e), in which symptomatic treatment with analgesics and bisphosphonates takes place. In the polyostotic form, only partial removal makes sense if important structures are compressed and patients develop complaints [7]. A typical finding in the CT-scan is ground-glass opacities [4, 8, 17]. 
Fig. 2 Primary neoplasia. $\mathbf{a}+\mathbf{b}$ Intraosseous meningioma $\mathrm{WHO}$ I. $\mathbf{c}+\mathbf{b}$ Meningioma WHO Grad III with infiltrative growth. e Intraosseous hemangioma. f Osteoma

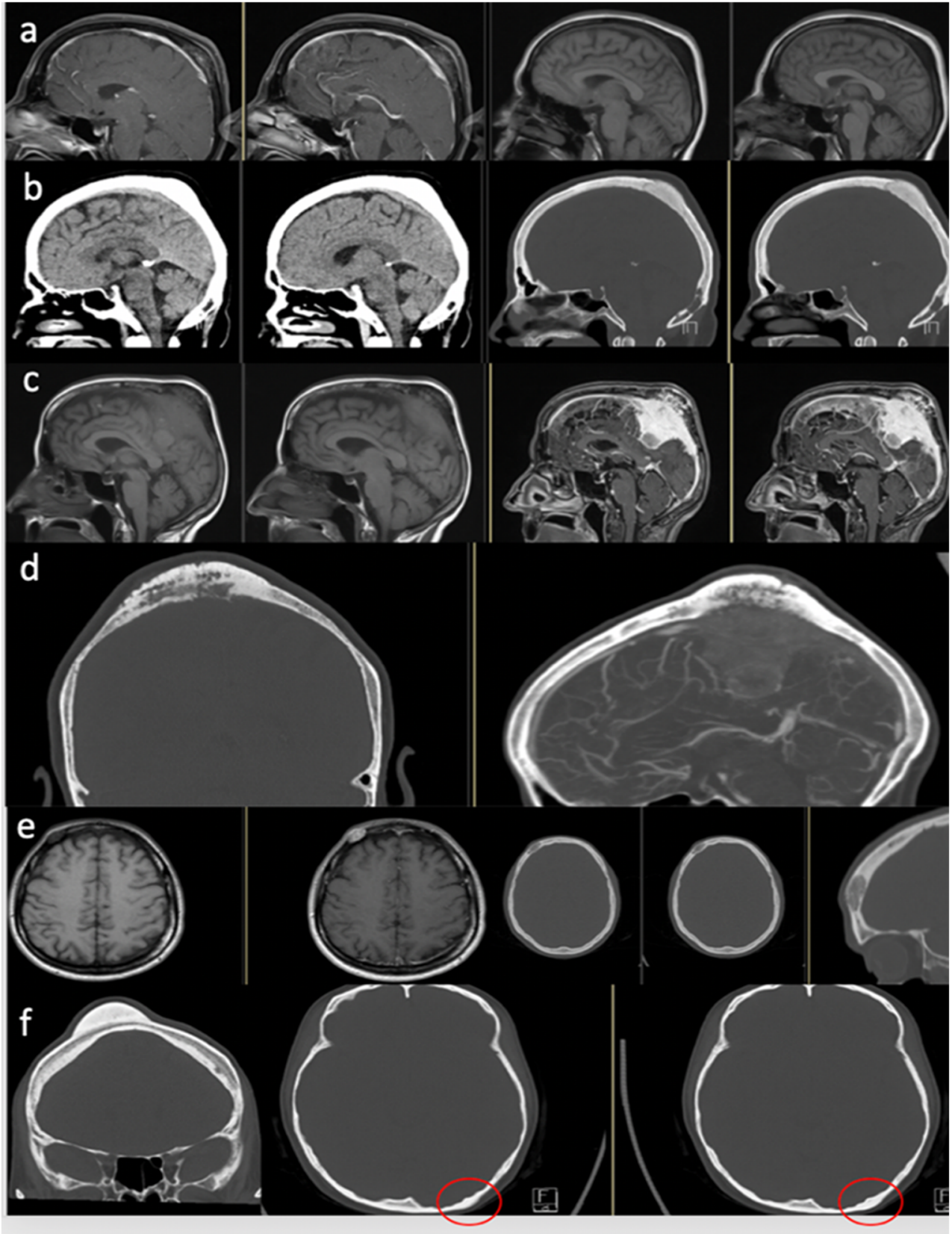

In our series, secondary, the bone-infiltrating lesions also occurred, such as squamous cell carcinoma and malignant melanoma (Fig. 3c). These, too, have an osteolytic growth; depending on the stage of the disease, the infiltration can range from the skin to intracranial. Surgical resection and cover of the defect with subsequent systemic adjuvant therapy must be planned [21, 24].

Based on the imaging, suspicions of the underlying lesion can be obtained (Table 1 and Figs. 2, 3, and 4). The limits of a lesion can suggest conclusions about the speed of growth: smooth edges and a homogeneous internal structure mark more of a benign, slowly growing process; irregular edges with inhomogeneous internal structure point, rather, to a malignant, fast-growing process. Also, slowly growing lesions are usually limited to the bone, while fast-growing show an infiltrating growth in adjacent tissue. With the administration of a contrast agent, further conclusions can be drawn about the dignity of the lesion. While reactive or scarring changes in the dura have a linear, homogeneous contrast enhancement, tumor infiltration is often characterized by irregular, inhomogeneous contrast enhancement. If the dura looks distant from the bone and, thus, the epidural space is visible, a dura infiltration is unlikely $[8,9,12,14,17]$.

The management of patients with calvarial lesions should be interdisciplinary, as with other oncological diseases. The general practitioner is usually the first contact for the patient, 

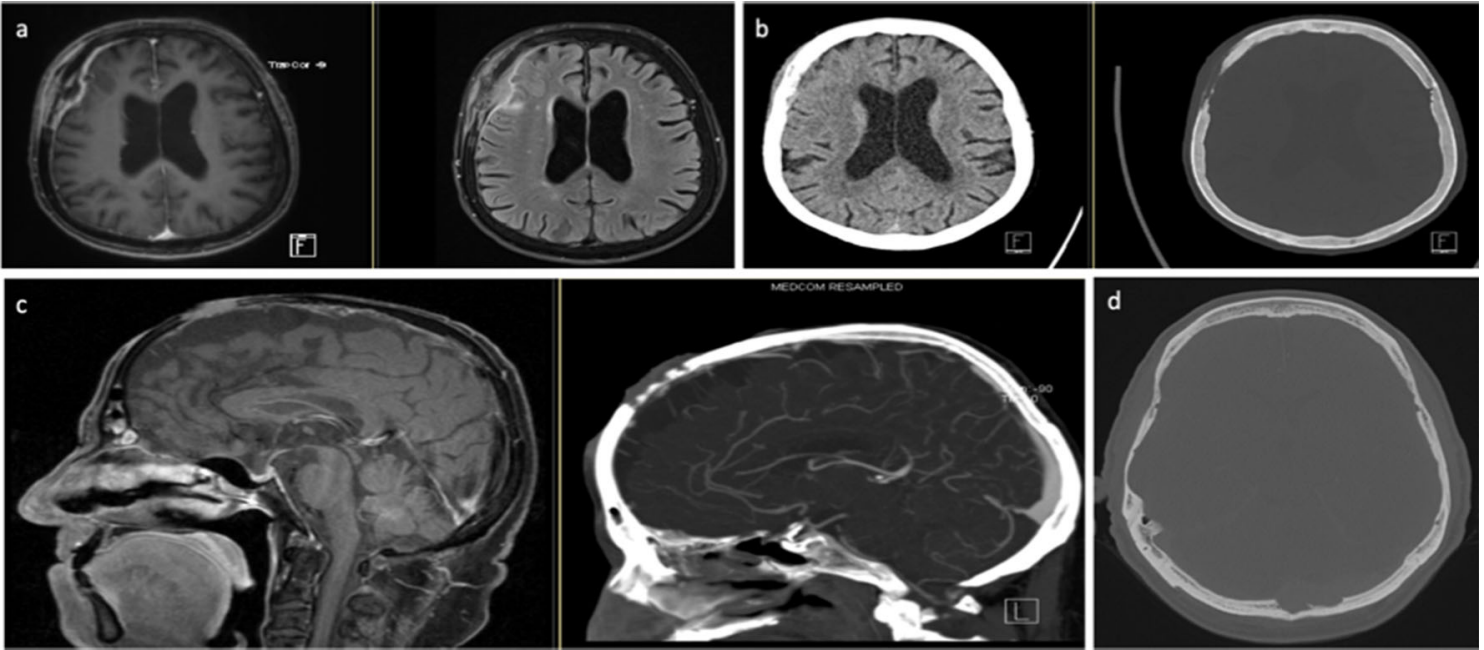

Fig. 3 Secondary neoplasia. a + b Metastasis. $\mathbf{c}$ Malignant melanoma with infiltrative growth and bone destruction. $\mathbf{d}$ Osteolytic lesion in plasmacytoma

as the lesions are often random results and there are no complaints. To draw conclusions about the possible entity of the lesion, a targeted image is required $[8,9,12,14,17]$. The suspected diagnoses can be limited and the further procedure planned. In any case, a surgical extraction of a tissue sample is necessary to ensure the diagnosis. If properly planned, the operation is a low-risk procedure without significant morbidity and mortality $[12,17,22]$. Important imaging aspects are, in particular, the extension of possible infiltration and the course of the large blood vessels, especially intracranially of the sinus. A precisely planned surgical procedure minimized the risks of bleedings and the intraoperative blood loss. Therefore, we recommend the implementation of a CT and MRI with and without contrast agent. In case of lesions near larger blood vessels, a CT or MR angiography or phlebography should also occur. Some lesions can have a similar extension on the bone, but differ significantly in their intracranial spreading (Fig. 2a-b vs c-d). The medical history, clinical complaints, and differential diagnoses must be taken into account together to evaluate the urgency of histological examination. While an underlying carcinoma requires a timely confirmation of a possible metastasis to initiate a targeted adjuvant treatment, in the case of a purely intraosseous lesion with a homogeneous internal structure and without any coreaction of the adjacent tissue and without any complaints, an initial follow-up observation is also acceptable and surgical care is not urgent. If an operation takes place, a complete resection with cover of the defect must be planned.
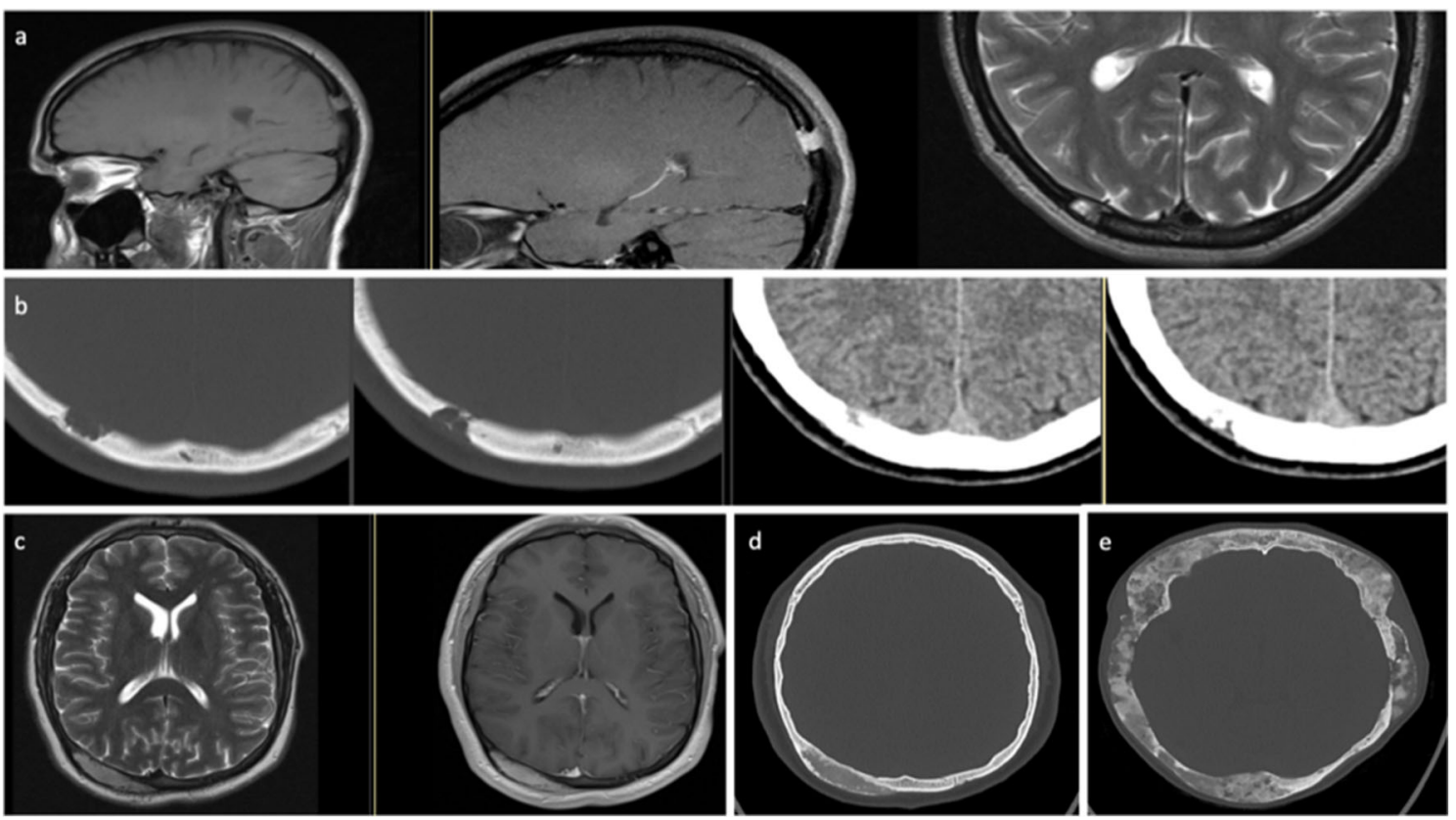

Fig. 4 Tumor-like lesions. a + b Histocytosis. $\mathbf{c}+\mathbf{d}$ Monostotic fibrous dysplasia. e Polyostotic fibrous dysplasia 
Author contribution All authors listed have made substantial, direct, and intellectual contribution to the work and approved it for publications. INK contributed to data acquisition, analysis, and interpretation of data, statistical analysis, and the writing of the first draft. JMD was responsible for the interpretation of imaging findings, the review, and critique of the final manuscript. FE was responsible for the conception and design, as well as the review and critique of the final manuscript. MT has contributed to the interpretation of the data, revising, and final approval of the manuscript.

Funding Open Access funding enabled and organized by Projekt DEAL.

Data availability All data are included in the manuscript.

\section{Declarations}

Ethics approval and consent to participate This retrospective study was approved by the ethics committee of the Eberhard Karls University Tuebingen (registration no. 028/2019BO2). All procedures performed were in accordance with the ethical standards of the institutional and/or national research committee and with the 1964 Helsinki Declaration and its later amendments or comparable ethical standards.

Written consent was obtained from the patients in order to evaluate and publish the data anonymously

Conflict of interest The authors declare no competing interests.

Open Access This article is licensed under a Creative Commons Attribution 4.0 International License, which permits use, sharing, adaptation, distribution and reproduction in any medium or format, as long as you give appropriate credit to the original author(s) and the source, provide a link to the Creative Commons licence, and indicate if changes were made. The images or other third party material in this article are included in the article's Creative Commons licence, unless indicated otherwise in a credit line to the material. If material is not included in the article's Creative Commons licence and your intended use is not permitted by statutory regulation or exceeds the permitted use, you will need to obtain permission directly from the copyright holder. To view a copy of this licence, visit http://creativecommons.org/licenses/by/4.0/.

\section{References}

1. Afghani T, Mansoor H (2018) Types of orbital osteoma - a descriptive analysis. Orbit 37:3-8. https://doi.org/10.1080/01676830. 2017.1353106

2. Berhouma M, Krichen W, Chamseddine A, Jemel H (2009) Surgical management of solitary eosinophilic granuloma of the calvaria. Two case reports. Neurochirurgie 55:555-559. https:// doi.org/10.1016/j.neuchi.2009.04.001

3. Bindal AK, Bindal RK, van Loveren H, Sawaya R (1995) Management of intracranial plasmacytoma. J Neurosurg 83:218221. https://doi.org/10.3171/jns.1995.83.2.0218

4. Bowers CA, Taussky P, Couldwell WT (2014) Surgical treatment of craniofacial fibrous dysplasia in adults. Neurosurg Rev 37:4753. https://doi.org/10.1007/s10143-013-0500-z
5. Chen TC (2016) Primary intraosseous meningioma. Neurosurg Clin N Am 27:189-193. https://doi.org/10.1016/j.nec.2015.11.011

6. Dong L, Zhang X, Zhang H, Song R, Gu X, He L (2013) Solitary plasmacytoma of the skull: two case reports. Oncol Lett 5:479-482. https://doi.org/10.3892/ol.2012.1046

7. Feller L, Wood NH, Khammissa RA, Lemmer J, Raubenheimer EJ (2009) The nature of fibrous dysplasia. Head Face Med 5:22. https://doi.org/10.1186/1746-160X-5-22

8. Garfinkle J, Melancon D, Cortes M, Tampieri D (2011) Imaging pattern of calvarial lesions in adults. Skelet Radiol 40:1261-1273. https://doi.org/10.1007/s00256-010-0971-8

9. Gomez CK, Schiffman SR, Bhatt AA (2018) Radiological review of skull lesions. Insights Imaging 9:857-882. https://doi.org/10. 1007/s13244-018-0643-0

10. Guo Z, Hu K, Zhao B, Bian E, Ni S, Wan J (2017) Osteosarcoma of the skull base: an analysis of 19 cases and literature review. J Clin Neurosci 44:133-142. https://doi.org/10.1016/j.jocn.2017.06.014

11. Gurbuz MS, Akmil MU, Akar E, Aker FV (2013) Solitary plasmocytoma of the skull. BMJ Case Rep 2013:bcr2013200379. https://doi.org/10.1136/bcr-2013-200379

12. Hong B, Hermann EJ, Klein R, Krauss JK, Nakamura M (2010) Surgical resection of osteolytic calvarial lesions: clinicopathological features. Clin Neurol Neurosurg 112:865-869. https://doi.org/ 10.1016/j.clineuro.2010.07.010

13. Kotecha R, Angelov L, Barnett GH, Reddy CA, Suh JH, Murphy ES, Neyman G, Chao ST (2014) Calvarial and skull base metastases: expanding the clinical utility of Gamma Knife surgery. J Neurosurg 121(Suppl):91-101. https://doi.org/10.3171/2014.7. GKS141272

14. Mitra I, Duraiswamy M, Benning J, Joy HM (2016) Imaging of focal calvarial lesions. Clin Radiol 71:389-398. https://doi.org/10. 1016/j.crad.2015.12.010

15. Mohindra S, Kapoor A, Mitra S, Nahar U (2016) Giant primary calvarial hemangioma over torcula: radiological features and operative nuances. Surg Neurol Int 7:S440-443. https://doi.org/10.4103/ 2152-7806.183544

16. Naama O, Gazzaz M, Akhaddar A, Belhachmi A, Asri A, Elmostarchid B, Elbouzidi A, Kadiri B, Boucetta M (2008) Cavernous hemangioma of the skull: 3 case reports. Surg Neurol 70:654-659. https://doi.org/10.1016/j.surneu.2007.05.052

17. Ozgiray E, Perumal K, Cinar C, Caliskan KE, Ertan Y, Yurtseven T, Oktar N, Ovul I, Oner K (2016) Management of calvarial tumors: a retrospective analysis and literature review. Turk Neurosurg 26: 690-698. https://doi.org/10.5137/1019-5149.JTN.12537-15.0

18. Prasanna GV, Katari UK, Vandanapu SK, Reddy MS, Adusumilli HB (2019) Giant calvarial cavernous hemangioma: a rare case report and review of literature. Asian J Neurosurg 14:578-580. https://doi.org/10.4103/ajns.AJNS_260_18

19. Rizea RE, Popescu M, Gheorghita KL, Popescu G, Neamtu MC, Busuioc CJ, Ciurea AV (2018) Neurosurgical rare disease: solitary plasmacytoma of the skull - case report and literature review. Romanian J Morphol Embryol 59:367-373

20. Samara A, Nepute J, Lu HC, Perrin RJ, Eldaya RW (2019) Calvarial Langerhans cell histiocytosis in an adult: typical imaging findings in an atypical age group. Radiol Case Rep 14:1478-1482. https://doi.org/10.1016/j.radcr.2019.09.009

21. Soma PF, Chibbaro S, Makiese O, Marsella M, Diemidio P, Fricia M, Passanisi M, Catania V, Sirago P, Ventura F (2008) Aggressive scalp carcinoma with intracranial extension: a multidisciplinary 
experience of 25 patients with long-term follow-up. J Clin Neurosci 15:988-992. https://doi.org/10.1016/j.jocn.2007.09.014

22. Stark AM, Eichmann T, Mehdorn HM (2003) Skull metastases: clinical features, differential diagnosis, and review of the literature. Surg Neurol 60:219-225; discussion 225-216. https://doi.org/10. 1016/s0090-3019(03)00269-6

23. Vital RB, Hamamoto Filho PT, Lapate RL, Martins VZ, de Oliveira LF, Romero FR, Zanini MA (2015) Calvarial ectopic meningothelial meningioma. Int J Surg Case Rep 10:69-72. https://doi.org/10.1016/j.ijscr.2015.03.033
24. Wollina U, Kittner T, Nowak A (2019) Nonmelanoma skin cancer with skull infiltration and cranial involvement. Open Access Maced J Med Sci 7:3030-3033. https://doi.org/10.3889/oamjms.2019.416

25. Yilmaz A, Musluman M, Aydin Y (2010) Primary osteolytic intraosseous meningioma of the frontal bone. Neurol Neurochir Pol 44:415-418. https://doi.org/10.1016/s0028-3843(14)60302-9

Publisher's note Springer Nature remains neutral with regard to jurisdictional claims in published maps and institutional affiliations. 